https://doi.org/10.46344/JBINO.2021.v10i03.24

\title{
PREPARATION AND IN-VITRO EVALUATION OF KETOTIFEN FUMARATE AS RECTAL SUPPOSITORIES
}

Hiba Muneer Faisal Kubba.,Rafid Mohammed Mohammed Hashim \& Fatima Jalal jawad Al_Gwahri

University of Baghdad College of Pharmacy

University of Uruk College of Pharmacy

University of Baghdad College of Pharmacy

\section{ABSTRACT}

Ketotifen Fumarate (KF) is an antihistamine with sedating effect that also has a stabilizing action on mast cell. It is used in the treatment of allergic conditions, and prophylactic management of asthma. The objective of this study was to prepare KF as suppository as an attempt to increase the bioavailability by avoiding the hepatic first pass metabolism. twelve formulas were prepared (ten conventional and two hollow) using fusion method and by using different bases such as polyethylene glycols of different (grades and ratios) and semisynthetic glyceride (SSG) as fatty base. The prepared suppositories were evaluated for physical properties such as weight variation, content uniformity softening time, melting time and hardness. In- vitro release profiles were also evaluated. The effect of the type of the base, the grade and ratio of PEGs mixture where evaluated. The effect of temperature and time of storage on the physical properties and the release profile of the suppository were studied. All of the prepared suppositories had acceptable physical properties and the maximum release of ketotifen (100\%, 99\%) was found from the F1 of PEGs 400:4000 (70:30) and F5 of PEGs 400:6000(70:30), respectively as a conventional suppositories. The release of drug from fatty based suppositories (SSG) was (51\%). It enhanced by adding non-ionic surfactant (tween80) to reach $75 \%$. The hollow suppositories F1l and F12 have faster release profile than the conventional one. Formulas F1 and F5 as conventional type suppositories and $\mathrm{Fll}$ as hollow type suppository were considered the good and suitable formulas because they exhibited a good physical properties with higher drug release. However, Fl was selected as the best one because it had excellent physical properties with highest \% of KF release.

Keywords: ketotifin fumarate, Conventional suppositories, Hollow suppository, Types of suppository bases. 


\section{Introduction}

Suppositories are solid dosage forms, intended for insertion into body orifices where absorption occurs. They melt at body temperature or dissolve in body fluid to exert local or systemic effects (1). Their action depends on the nature and the concentration of the drug and base. The suppositories where formulated to avoid patient gastrointestinal tract problems, unpleasant taste or bad smelling drugs, first pass effect and their convenience for children and unconscious patients $(2$, 3). Rectal suppositories are formulated in different shape and size (usually 1-2g). They contain one or more active substances dispersed or dissolved in a suitable base that may be soluble or dispersible in water or may be melting at body temperature (4). Ketotifen Fumarate is Histamine $\mathrm{Hl}$ receptor antagonist. It is designated chemically as 4-(1-Methylpiperidin-4-ylidene)

$4 \mathrm{HbenzO}[4,5]$ cyclohepta $[1,2-\mathrm{b}]$ thiophen-10(9H)-one monofumarate (5). Ketotifen Fumarate available as a white to light yellowish white crystalline powder. It is sparingly soluble in methanol and in acetic acid, and slightly soluble in water, in ethanol and in acetic anhydride. Melting point: about 191-195 ${ }^{\circ} \mathrm{C}$, pKa: 8.75 and Log P (octanol/water): 4.99 (6). Ketotifen Fumarate is almost completely absorbed from the gastrointestinal tract after oral doses, but bioavailability is reported to be only about $50 \%$ due to hepatic first-pass metabolism. It is used in the treatment of allergic conditions such as rhinitis and conjunctivitis. Ketotifen has also been used in the prophylactic management of asthma (7).

\section{Material and Methods}

\section{Material}

Ketotifen Fumarate (gift from AlShara al-Awsat factory , Iraq), Disodium hydrogen phosphate (Seelze - Hoover ,Germany),Lactose powder (Hazard Ltd ,England), Liquid paraffin (Fluka AG Switzerland), Polyethylene glycols 1000,4000 and 6000 (BDH Chemicals Ltd, England), Polyethylene glycols 400 (Searle Company, England) ,Polyethylene glycols 600 (Hazard Ltd ,England) ,Potassium dihydrogen phosphate (Hazard Ltd England), Propylene glycol (Merck Shuchardt, Germany), Semi synthetic glyceride(DUB PP DL1) (Stearinerie Dubois Company gift from Al-Safa factory, Iraq)

\section{Methods}

Preparation of ketotifen fumarate suppositories

Two types of KF suppositories were prepared

\section{Conventional suppositories}

2. Hollow-type suppositories containing KF solution or powder form.

\section{Preparation of ketotifen conventional suppositories}

Ketotifen Fumarate conventional suppositories were prepared by the fusion method using different types of bases, as shown in table (1). In fusion method the suppository base was melted at appropriate temperature, and then KF was added. Uniform 
dispersion was formed in the melted base which was then poured in a metal mold, allowing it to cool and congeal into suppositories. Then after, suppositories were removed from the mold, wrapped in aluminum foil and stored in the refrigerator until use (8).

\section{Table (1) Composition of KF Conventional Suppositories}

\begin{tabular}{lll|}
$\begin{array}{l}\text { Formulas } \\
\text { No. }\end{array}$ & $\begin{array}{l}\text { Quantity of } \\
\text { ketotifen }(\mathrm{mg})\end{array}$ & $\begin{array}{l}\text { Type of the Base } \\
(\mathrm{w} / \mathrm{w})\end{array}$ \\
\hline 1 & 1 & PEGs 400:4000 (70:30) \\
\hline
\end{tabular}

\begin{tabular}{|l|l|l|}
\hline 2 & 1 & PEGs 600:4000 (50:50) \\
\hline 3 & 1 & PEGs 1000:4000 (70:30) \\
\hline 5 & 1 & PEGs 1000:4000 (50:50) \\
\hline 6 & 1 & PEGs 400:6000 (70:30) \\
\hline 7 & 1 & PEGs 600:6000 (50:50) \\
\hline 8 & 1 & PEGs 1000:6000(70:30) \\
\hline 9 & 1 & Semisynthetic glyceride(SSG) \\
\hline 10 & 1 & SSG+1\% Tween 80 \\
\hline
\end{tabular}

Preparation of hollow-type suppositories containing ketotifen in solution or powder forms

Hollow-type suppositories were prepared (table 2) by melting various suppository bases using gentle heat on a water bath, then the melted bases were poured into $2 \mathrm{~g}$ suppository molds equipped by cylindrical tube in the center and allowed to stand for 2 hours at room temperature to solidify. After construction of a hollow cavity in the solidified bases, ketotifen in the following forms was added to the cavity:
$1.38 \mathrm{mg}$ of ketotifen powder mixed with lactose powder (used as filler) in ratio (1:9) (9).

$500 \mu \mathrm{L}$ of $1.38 \mathrm{mg}$ of ketotifen solution prepared by dissolving in propylene glycol (10).

Each suppository contained an amount of solution or powder equivalent to 1.38 ketotifen fumarate. The openings at the back part of the suppositories were sealed with the same melted bases then left for another two hours to congeal. 
Table (2) Composition of Ketotifen Hollow-Type Suppositories

\begin{tabular}{lll}
\hline Formula No. & $\begin{array}{l}\text { Quantity of } \\
\text { ketotifen }\end{array}$ & Type of the Base
\end{tabular}

\section{(mg)}

\begin{tabular}{|l|l|l|}
\hline 11 & 1 & PEGs 400:4000 (70:30) \\
\hline 12 & 1 & SSG \\
\hline
\end{tabular}

\section{Evaluation of the physical properties of suppositories}

\section{Drug Content Uniformity}

Determination of suppositories drug content was done by dissolved the suppository in $100 \mathrm{ml}$ phosphate buffer at $\mathrm{pH} 7.4$ by stirring through magnetic stirrer slowly at $37^{\circ} \mathrm{C}$ for $30 \mathrm{~min}$, then the solution was filtered and the filtrate was diluted suitably and absorbance was measured spectrophotometrically at the drug suitable $\lambda$ max (11).

\section{Breaking strength}

Erweka hardness tester has been used to make this test to determine the resistance of suppositories to rupture, and it was measured by the mass needed to rupture them by crushing.

The suppository was placed into the holding device with the tip upwards and the test chamber was then closed with glass plate, the temperature inside the chamber should be set at $25^{\circ} \mathrm{C}$. At this point, the initial load, which was given by the weight of the entire suspended block, was $600 \mathrm{~g}$. then adding of $200 \mathrm{~g}$ disc every minute, the suppository collapsed completely under the pressure of the mass. If the suppository collapsed within 20 seconds of placing the last disc, then this mass was not taken into account. If the suppository collapsed between 20 and 40 seconds of placing the last disc, then half of this mass was used in calculation, i.e. $100 \mathrm{~g}$, if the suppository withstands pressure for more than 40 seconds after last disc was placed, then all the mass was used in calculation. Ten suppositories were used in each measurement (11).

\section{Melting time determination}

This test measured the time taken for the entire suppository to melt or 
disperse. The prepared suppositories were placed into a glass tube measuring ( $2.5 \mathrm{~cm}$ diameter) containing $2 \mathrm{ml}$ of phosphate buffer solution at $\mathrm{pH}$ 7.4. The tube was placed in a water bath at $37^{\circ} \mathrm{C} \pm 0.5^{\circ} \mathrm{C}$. The time needed for the suppository to melt or disperse was measured $(11,12)$.

\section{Softening time determination (for lipophilic suppositories)}

Liquefaction time or softening time was measured using a pipette having a broad opening on one side and a narrow opening on the other; suppository was pushed inside from the broad end side to reach to the narrow end. $5 \mathrm{ml}$ of phosphate buffer $\mathrm{pH} 7.4$ was placed inside the pipette, maintained at $37 \pm 0.5^{\circ} \mathrm{C}$. A thin iron rod is placed on the top of the suppository and the time at which the iron rod just inserts into the suppository is recorded as liquefaction time. This indicates the time taken by the formulation to liquefy under similar pressures found in rectum $(13,14)$.

\section{In-vitro drug release}

The release rates of ketotifen from conventional and hollow-type suppositories were determined by using USP paddle dissolution apparatus .

The suppository placed in a jar containing $300 \mathrm{ml}$ Sorensen's phosphate buffer $\mathrm{pH}$ (7.4), with a paddle rotating at 50 r.p.m at a constant temperature of $\left(37^{\circ} \mathrm{C} \pm 0.5^{\circ} \mathrm{C}\right)(11)$.
The dissolution test was carried out for 60 minutes. At appropriate time intervals $(0,5,10,15,20,25,30,40,50$ and 60 minutes), 3-ml samples were withdrawn through Millipore filter syringe, the volume of the dissolution medium was kept constant by replacing the withdrawn volume of the sample with equal volume of fresh dissolution medium maintained at the same temperature. A minimum of triplicate drug release determinations were made for each suppository preparation. The drug samples were analyzed using an ultraviolet spectrophotometric method and percent of drug release was determined $(11,13)$.

\section{Variables affecting physical properties and drug release}

Different formulas of $\mathrm{KF}$ suppositories were prepared as shown in tables 1, 2 in order to study different factors affecting the physical properties and in- vitro release of the drug.

\section{Effect of base type}

Hydrophilic bases (PEG 400, 600, 1000, 4000 and 6000) in different proportion for formula (1 to 8) and fatty bases (SSG) F9 were used to investigate the effect of type of suppository base on the physical properties and in-vitro release of the prepared suppositories.

Formulas 1 and 11 were selected to demonstrate this effect by using PEG base as a hydrophilic base and F9 and F12 selected to demonstrate this effect by using an oleaginous base. 
Effects of the grade and ratio of polyethylene glycols (PEGs)

The effect of changing the grade and ratio of polyethylene glycols as a suppository base on the physical properties and the drug release was studied. This was done by changing the grade and/or ratio of polyethylene glycol as in F1-F8.

\section{Effect of surfactant on the release of drug from fatty bases}

The effect of adding a surface active agent (Tween 80) for F10 on the release of drug and the physical properties of suppositories was studied.

Effect of the types of suppositories:

Three types of suppositories were prepared to investigate the influence of suppository type on their physical properties and the percentage release of ketotifen from them. The first type is conventional suppositories, while the second and the third types are hollow-types suppositories containing ketotifen in powder and in solution forms, respectively.

\section{Effect of storage time and temperature on the physical properties and in-vitro release of ketotifen fumarate of the selected formula}

To study the effect of storage time and temperature on physical properties and drug release of selected formula. The prepared suppositories were stored at $4^{\circ} \mathrm{C}$ and $25^{\circ} \mathrm{C}$ for 30 days. The suppositories were wrapped with aluminum foil, placed in tightly closed containers and stored at the mentioned temperatures for 30 days (12).

\section{Result and discussion}

\section{Evaluation of the physical parameters of the prepared suppositories}

\section{All the prepared suppository} formulas were homogeneous, free from pits, fissures and cracks. The longitudinal section of the suppositories was plain and clear; there was no migration of active ingredients, fat blooming and exudation .

Table (3) represent the formulas F1 - Flo concerning the physical properties including, weight variation, content uniformity, hardness, melting time and softening time of the prepared formulas.

Table (3) showed that all the prepared suppositories content uniformity were within the permissible range, indicating uniformity of drug dispersion in suppositories. The preparations met the criteria of British Pharmacopeia content uniformity (85$115) \%$ of the label claim (15). The weight variations for all formulas were found to be within the acceptable limits with allowable percent less than (5\%) which indicated that calibration of mold was highly acceptable (15). The suppositories possessed good hardness for handling and transportation. In table (3), all suppositories exhibited hardness in the range of $2.6-3.4 \mathrm{~kg} / \mathrm{cm} 2$ which 
required for handling and transportation

Table (3): Physical Property of The Prepared Suppositories

\begin{tabular}{|c|c|c|c|c|c|c|}
\hline $\begin{array}{l}\text { F. } \\
\text { no. }\end{array}$ & Base type & $\begin{array}{l}\text { Weight } \\
\text { (g) }\end{array}$ & $\begin{array}{c}\text { Content } \\
\text { uniformit } y \\
\%\end{array}$ & $\begin{array}{r}\text { Hardness } \\
\mathrm{kg} / \mathrm{cm}^{2}\end{array}$ & $\begin{array}{l}\text { Melting } \\
\text { time } \\
2(\mathrm{~min})\end{array}$ & $\begin{array}{l}\text { Softening } \\
\text { time } \\
\text { (min) }\end{array}$ \\
\hline 1 & $\begin{array}{l}\text { PEGs 400:4000 } \\
(70: 30)\end{array}$ & 2.18 & 106 & 2.6 & 25 & - \\
\hline 2 & $\begin{array}{l}\text { PEGs 600:4000 } \\
(50: 50)\end{array}$ & 2.14 & 105 & 2.8 & 27 & - \\
\hline 3 & PEGs 1000:4000 & 2.28 & 103 & 3.0 & 30 & - \\
\hline
\end{tabular}

\begin{tabular}{|c|c|c|c|c|c|c|}
\hline & $(70: 30)$ & & & & & \\
\hline 4 & $\begin{array}{c}\text { PEGs 1000: } 4000 \\
(50: 50)\end{array}$ & 2.28 & 98 & 3.2 & 32 & - \\
\hline 5 & $\begin{array}{c}\text { PEGs 400: } 6000 \\
(70: 30)\end{array}$ & 2.19 & & & & \\
\hline 6 & $\begin{array}{l}\text { PEGs 600: } 6000 \\
(50: 50)\end{array}$ & 2.15 & 104 & 2.9 & 29 & - \\
\hline 7 & $\begin{array}{l}\text { PEGs 1000: } 6000 \\
(70: 30)\end{array}$ & 2.28 & 96 & 3.2 & 31 & - \\
\hline 8 & $\begin{array}{l}\text { PEGs 1000: } 6000 \\
(50: 50)\end{array}$ & 2.29 & 103 & 3.3 & 34 & - \\
\hline 9 & SSG & 1.92 & 95 & 3.4 & 20 & 13 \\
\hline 10 & $\begin{array}{l}\text { SSG+1\% Tween } \\
80\end{array}$ & 1.89 & 97 & 3.3 & 17 & 10 \\
\hline
\end{tabular}

Effect of the type of the base on melting and softening time

In table (3) the results showed that the melting time of fatty based suppositories (SSG) was shorter than hydrophilic based suppository (PEGs). The reason of this result was the rapid melting of fatty bases at experimental temperature while the hydrophilic bases need more time to soften and dissolve (16). 
The softening time of fatty based suppository decrease with the addition of surfactant, surfactants decreased the viscosity and increased the wettability of the fatty base (17).

\section{Effect of the grade of PEGs on the hardness and melting time}

Table (3) showed the effects of changing the grade of polyethylene glycols on the physical properties of conventional suppositories. The hardness and melting time of $\mathrm{Fl}$ was found to be (2.6 kg/cm2) and (25min.) respectively, while higher hardness $(3 \mathrm{~kg} / \mathrm{cm} 2)$ and higher melting time (30min.) were recorded from $\mathrm{F3}$ at $(70: 30)$ ratio. Also the hardness $(2.8 \mathrm{~kg} / \mathrm{cm} 2)$ and melting time (27min.) of F5 were found to be less than F7 (3.2 kg/cm2) (31 min.), at the same ratio (70:30). Same results were indicated when comparing F2 with F4, F6 with F8 at a ratio of (50:50). This may be attributed to the fact that the increasing of the molecular weight of PEGs (by polymerization) leads to increasing the melting time and the hardness of the polymer (18).

\section{Effect of the ratio of PEGs on the hardness and melting time}

The results of the hardness

(3kg/cm2) and melting time (30 min.) of F3 showed to be less than F4

(3.2kg/cm2), (32 min.) for the same base type PEGs 1000:4000 with different ratio (70:30) and (50:50), respectively. Also, the result of $\mathrm{F} 7$ hardness $(3.2 \mathrm{~kg} / \mathrm{cm} 2)$ and melting time (31 $\mathrm{min}$.) is showed to be less than F8 $(3.3 \mathrm{~kg} / \mathrm{cm} 2)$, (34min.) for the same base type PEGs 1000:6000 at different ratio (70:30) and (50:50), respectively. It was obvious that increasing the concentrations of the high molecular weight polyethylene glycols and decreasing the concentration of the low molecular weight PEGs in the base resulted in rising the melting time and increasing the hardness of the base (19).

\section{Effect of the type of suppository on hardness and melting time}

Table (4) showed the effect of changing the suppository type on the physical properties of the resultant suppositories using $\mathrm{Fl}$ and $\mathrm{F} 9$ (conventional) and Flland F12 (hollow) type. The results indicated that the melting time and hardness of the hollow-types suppositories, formulas 11 and 12, were less than those of the conventional type Fland F9. This effect may be attributed to presence of cavities fill of drug which might affect the skeleton structure of the hollow-type suppositories in comparison with the compact back bone of the conventional type with the more rigid and consolidated structure than the hollow-type (10). 
Table (4) Physical Properties of KF Hollow and Conventional Suppositories.

\begin{tabular}{llll}
\hline F. & Drug & Type of & Melting Hardnes \\
no. Type of base & $(\mathrm{mg})$ & suppository & time $(\mathrm{min}) \mathrm{s}\left(\mathrm{kg} / \mathrm{cm}^{2}\right)$
\end{tabular}

\begin{tabular}{|c|c|c|c|c|c|}
\hline 1 & $\begin{array}{c}\text { PEGs } 400: 4000 \\
(70: 30)\end{array}$ & 1 & Conventional & 25 & 2.6 \\
\hline 9 & SSG & 1 & conventional & 20 & 3.4 \\
\hline 11 & $\begin{array}{c}\text { PEGs } 400: 400 \\
(70: 30)\end{array}$ & 1 & Hollow & & \\
\hline 12 & SSG & 1 & Hollow & 11 & $\overline{2.6}$ \\
\hline
\end{tabular}

\section{Evaluation of in- vitro drug release}

\section{Effect of the type of the base}

Figure (1) represents the effect of the type of suppository base on the release of KF. Depending on the results obtained, it was found that the release rate was greater for suppositories prepared from hydrophilic bases (F 1 to 8 ), than those prepared from fatty bases formula F9 and F10. This may be due to the fact that KF is slightly soluble in water and it's affinity for hydrophilic bases is less in comparison with the fatty bases, so it leaves the hydrophilic bases easily into the dissolution medium, the results were in consistence with the release of tindazole from hydrophilic and fatty bases suppository ${ }^{(16)}$.

Drug partitioning is a function of the nature of base and it corresponds to the affinity of the drug toward the bases. Therefore, if there is low affinity between the drug and the base, the release rate of the substances having low solubility in aqueous media from hydrophilic bases will be high ${ }^{(20)}$ 
Figure (1): Effect of type of suppository bases on the in- vitro release of KF from conventional suppositories [F9 (SSG), F1 (PEGs 400:4000 70:30), F5 (PEGs 400:6000 70:30)] in phosphate buffer at $\mathrm{pH} 7.4$ and $37^{\circ} \mathrm{C}$.

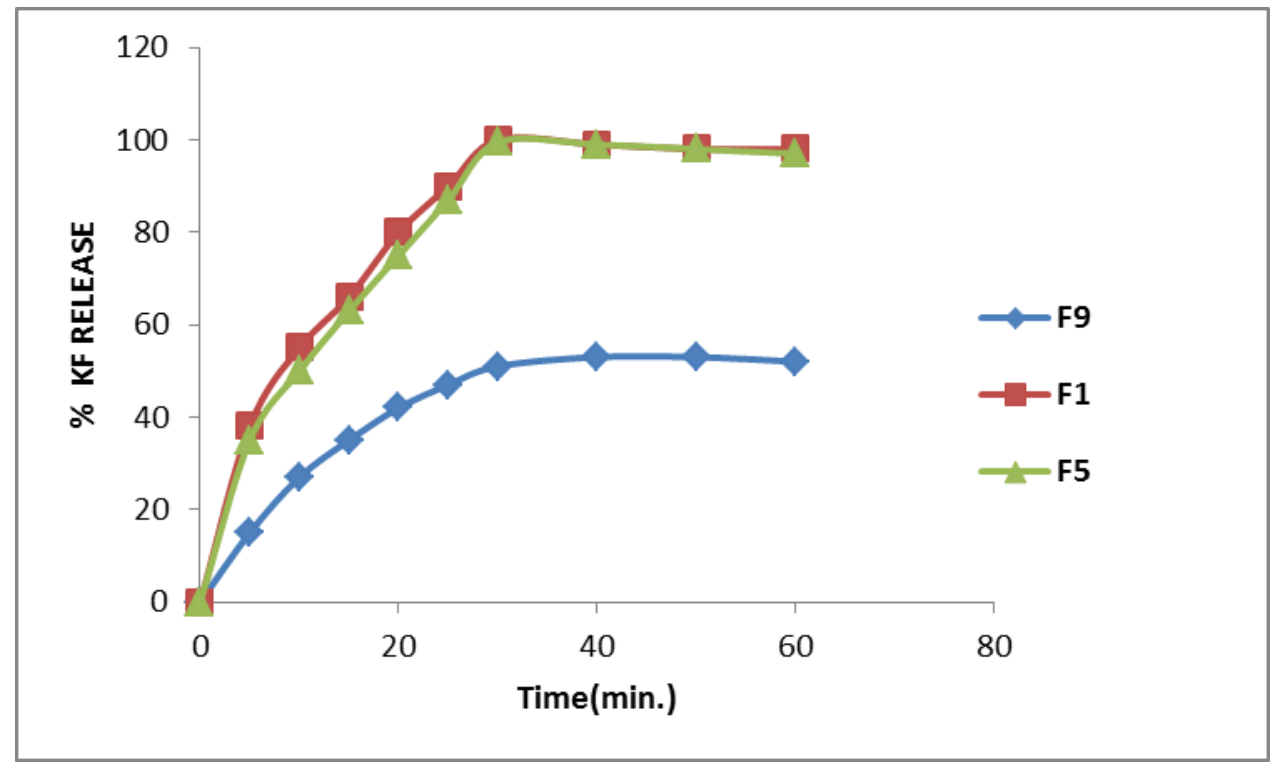

\section{Effect of the grade of PEGs}

The results demonstrated in the figure (2) and (3) show that when the molecular weight of PEGs increased by changing the grade led to a decrease in the release of KF. These results may be attributed to that, the water solubility and hygroscopicity of PEGs decrease with increase average molecular weights of them ${ }^{(20)}$. 


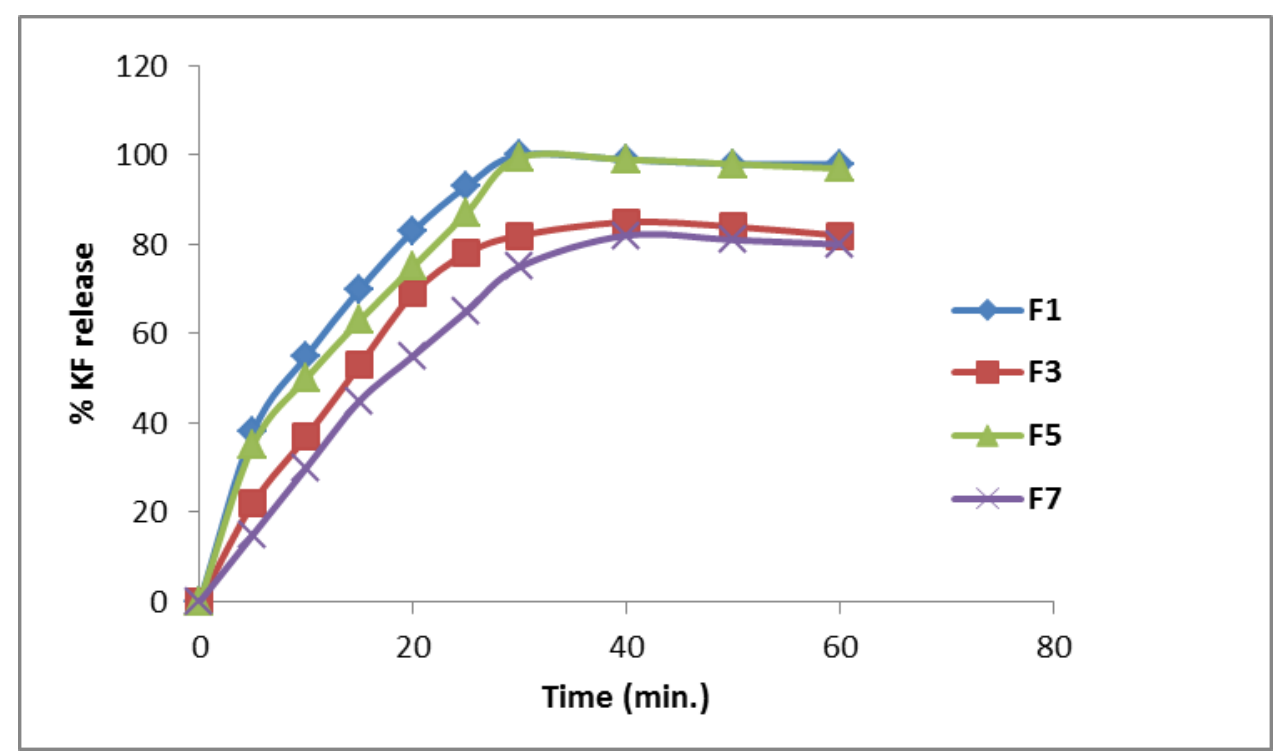

Figure (2): Effect of the grade of PEGs [F1 (PEGs 400:4000), F3 (PEGs 1000:4000), F5 (PEGs 400:6000) and F7 (PEG 1000:6000)] at a constant ratio (70:30) on the invitro release of $\mathrm{KF}$ in phosphate buffer 7.4 at $37^{\circ} \mathrm{C}$.

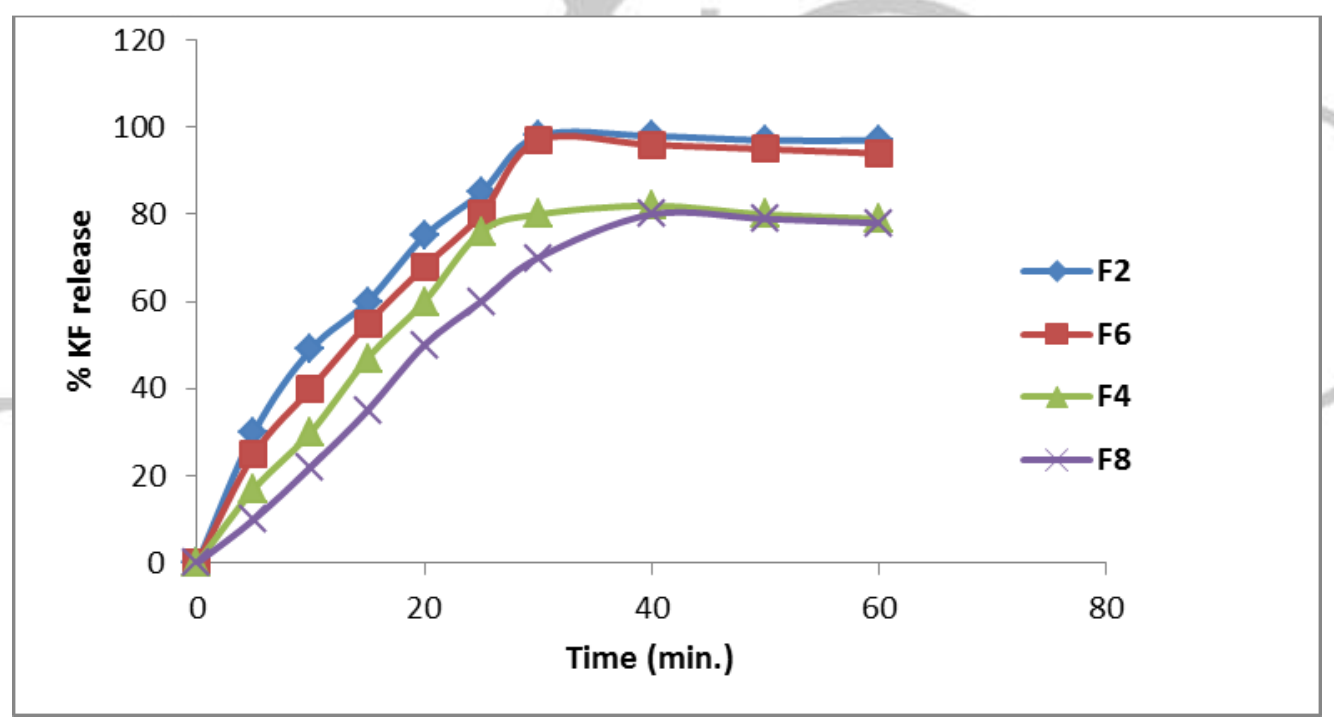

Figure (3): Effect of the grade of PEGs of [F2 (PEGs 600:4000), F6 (PEGs 600:6000), F4 (PEGs 1000:4000), and F8 (PEGs 1000:6000) at a constant ratio (50:50) on release of $\mathrm{KF}$ in phosphate buffer 7.4 at $37^{\circ} \mathrm{C}$.

Formula 1 exhibited the highest drug release as it contained low concentration of PEG4000 (30\%) and high concentration of PEG400 (70\%). At the same time F5 exhibited the highest drug release as it contain low concentration of PEG6000 and high concentration of PEG400 at a ratio 
(70:30), as shown in figure (4). The same result was obtained when these bases were used in the formulation of domperidone rectal suppositories ${ }^{(19)}$.

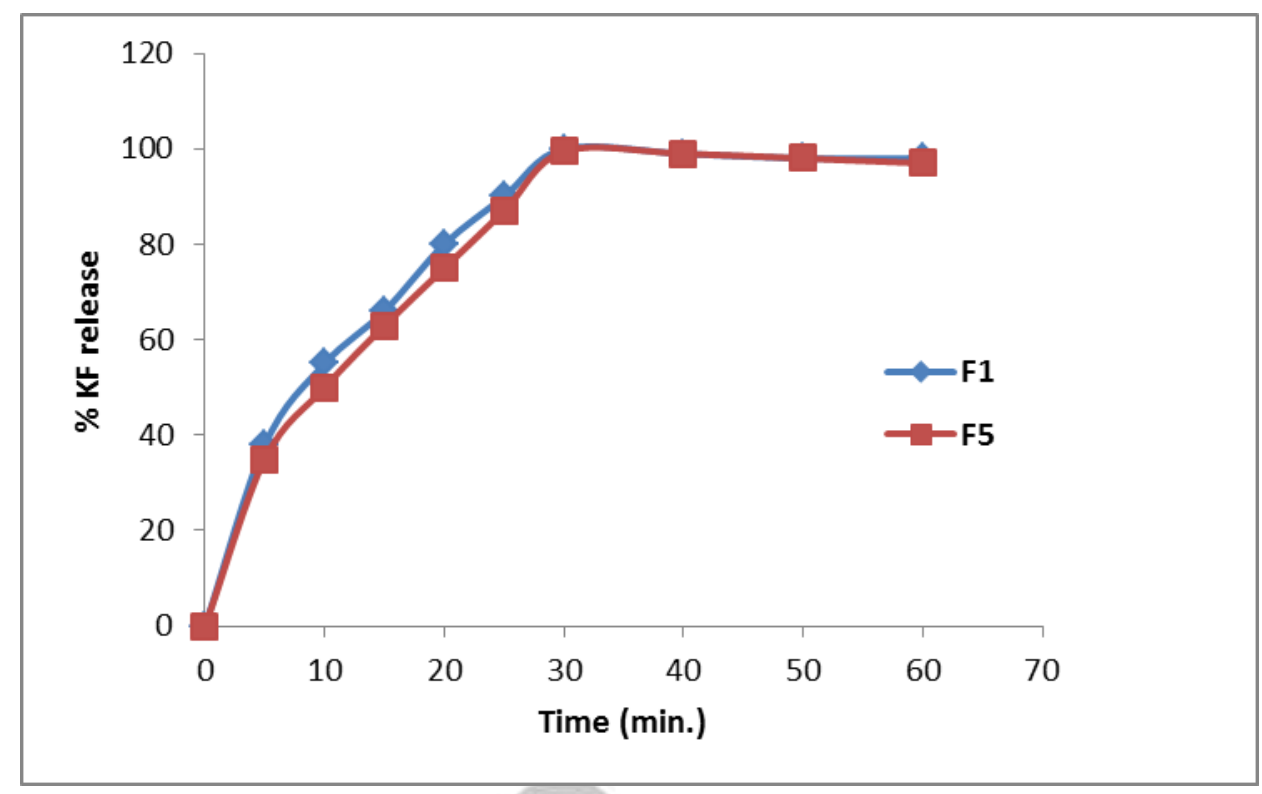

Figure (4): Effect of the grade of PEGs on release of KF from [F1 (PEGs 400:4000 70:30), F5 (PEGs 400:6000 70:30)] in phosphate buffer pH 7.4 at 37 0C.

\section{Effect of the ratio of PEGs}

The results showed that the increase of the ratio of high molecular weight and decrease the ratio of low molecular weight of PEGs lead to decrease the release of the drug ${ }^{(19)}$ as shown in figure (5)

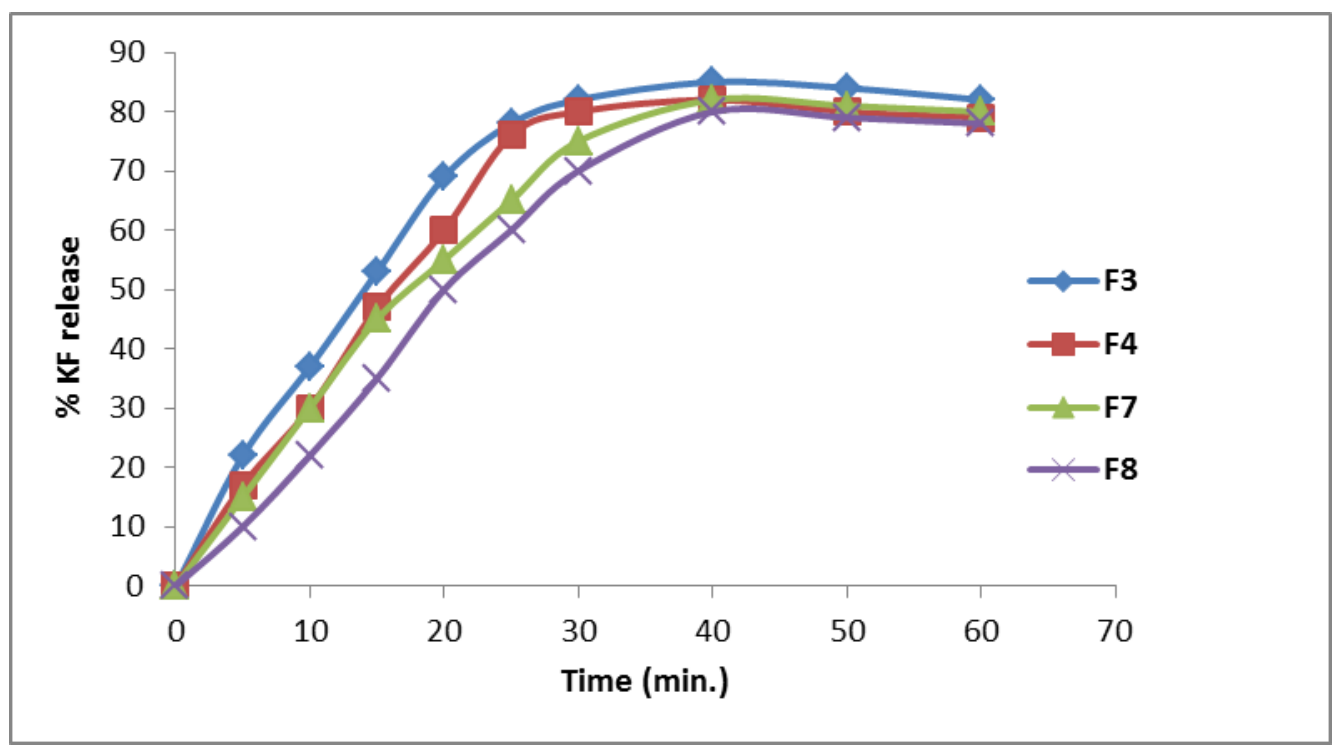


Figure (5): Effect of the ratio of PEG on the release of KF [F3 (PEGs 1000:4000 70:30), F4 (PEGs 1000:4000 50:50,) F7 (PEGs 1000:4000 70:30) and F8 (PEGs 1000:6000 50:50) in phosphate buffer at pH 7.4 at $37{ }^{\circ} \mathrm{C}$.

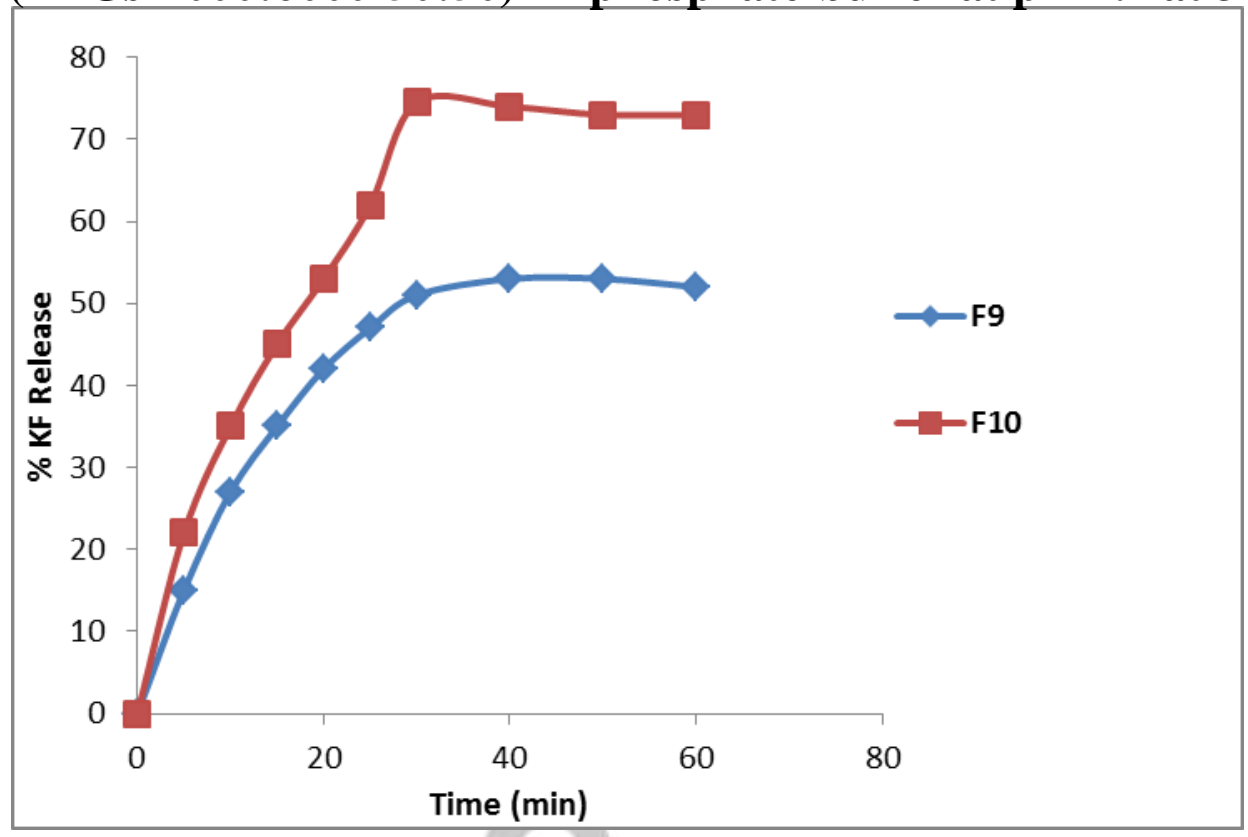

\section{Effect of surfactant}

Figure (6) showed low percent of release of $\mathrm{KF}$ from fatty base (SSG) of F9 due to the fact that lipophilic drug such as KF has a high affinity to fatty bases.

Addition of surfactant Tween 80 (1\%) in formula F10 increased the release clearly to $75 \%$ after $30 \mathrm{~min}$. This was explained by previous study, it was stated that, surfactants induce more channels for drug release, thus increasing the effective porosity of the base. These results were in agreement with miconazole nitrate suppositories formulation 121 .

The HLB value of a surfactant (Tween $80=15$ ) provides an indication of the hydrophilic-lipophilic balance of the compound and the higher the HLB value, the more hydrophilic of the compound. In addition, an increase in the hydrophilic character of a fatty base may reduce the affinity of a base for lipophilic substances, thereby promoting drug release (22).

On the other hand, surfactant lead to increasing the surface area of the suppository mass, as a result of their moistening effects, shortening disintegration times of lipophilic suppositories with changing their lipophilic characteristics to a lipohydrophilic nature (23). 
Figure (6): Effect of surfactant on invitro release of KF from fatty based $\begin{array}{llll}\text { suppositories [F9 } & \text { (SSG), } & \text { F10 }\end{array}$ (SSG+1\%Tween 80)]

\section{Effect of type of suppository}

Figure (7) showed the release behavior of $\mathrm{KF}$ from conventional $\mathrm{Fl}$ and hollow suppositories F1l. It indicated that there was an increase of drug release for the hollow type $\mathrm{Fll}$ in comparison with conventional $\mathrm{Fl}$. This result is due to the low melting time of hollow type in comparison with the conventional one. On the other hand, the presence of lactose as a filler at a ratio (1:9) leads to enhance KF dissolution (24).

Figure (8) showed the release behavior of KF using fatty base (SSG). The release profile of the drug from the fatty base was increase in the hollow type suppository (95\%) comparison type(51\%).This result may be contributed to that the hollow type suppository is expected to decrease the interaction between the drug and the base material (25).

This is in agreement with Watanabe.et.al demonstration of that drug is more rapidly release from a hollow suppository than from a conventional suppository (26). 


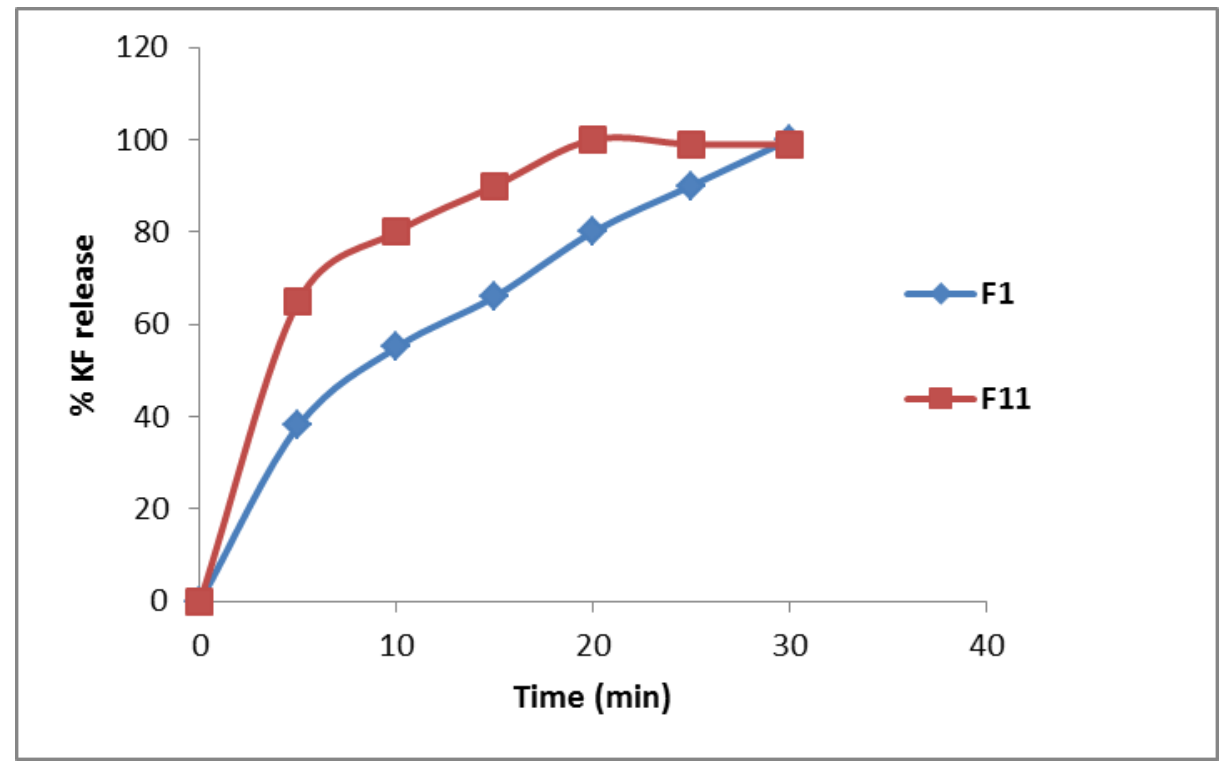

Figure (7): Effect of suppository type on the in- vitro release of KF [F1 (PEGs400:4000 70:30 as conventional) and F11 (PEGs 400:4000 70:30 as hollow)] in phosphate buffer $\mathrm{pH} 7.4$ and $37^{\circ} \mathrm{C}$.

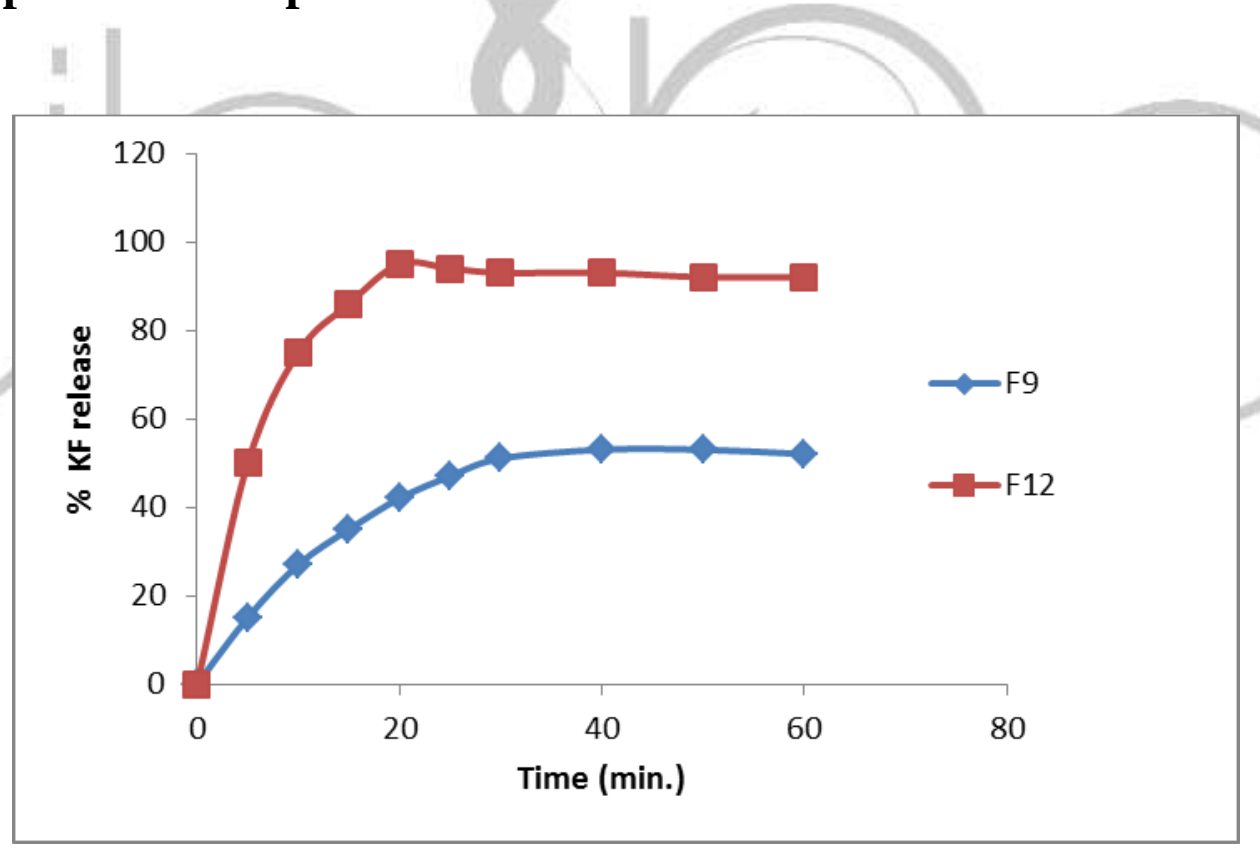

Figure (8): Effect of suppository type on the in- vitro release of KF from [F9 SSG (conventional) and F12 SSG (hallow)] suppositories in phosphate buffer $\mathrm{pH} 7.4$ at $37^{\circ} \mathrm{C}$.

Effect of storage time and temperature on the release of $\mathrm{KF}$ 
Conventional type suppositories F1 was chosen as the most appropriate formula since, it showed a faster drug release and acceptable physical properties in comparison with other conventional formulas. Therefore, the effect of storage time and temperature was done on it . Samples were selected from this formula and stored for 30 days at $4^{\circ} \mathrm{C}$ and $25^{\circ} \mathrm{C}$. The results indicated that on storage of these suppositories samples of $\mathrm{F} 1$ at $4^{\circ} \mathrm{C}$ showed increase the melting time from 25 to $27 \mathrm{~min}$ and the hardness from 2.6 to $2.8 \mathrm{~kg} / \mathrm{cm} 2$. On the other hand, the storage of the samples of $\mathrm{F} 1$ at $25^{\circ} \mathrm{C}$ decreases the melting time to $23 \mathrm{~min}$. and the hardness to $2.4 \mathrm{~kg} / \mathrm{cm} 2$. The dissolution behavior of $\mathrm{KF}$ from stored samples at a various temperatures showed slight change in the dissolution profile as shown in figure (9).

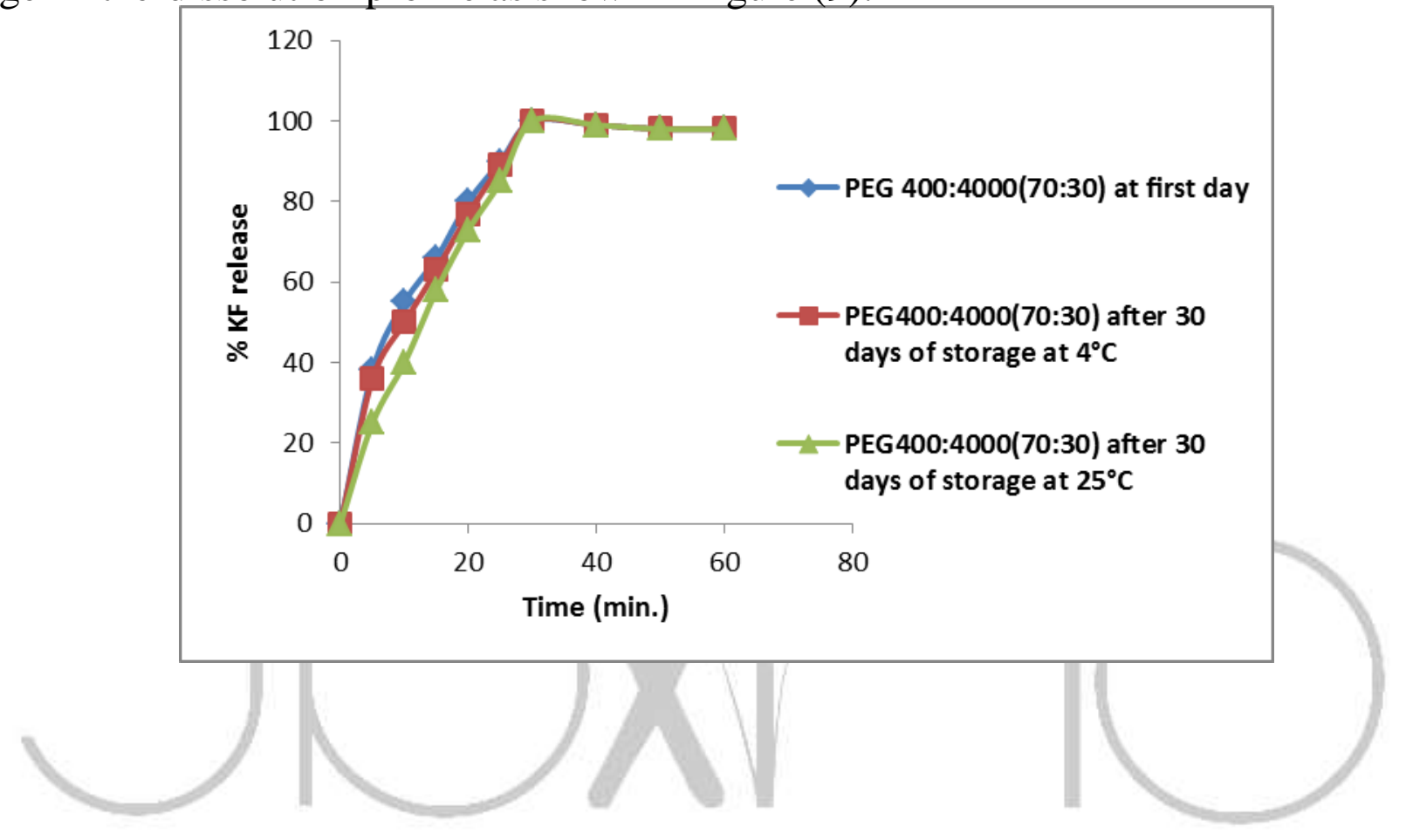

Figure (9): Effect of storage at different temperatures on the release of $\mathrm{KF}$ from F1 (PEGs 400:4000 70:30) in phosphate buffer at $\mathrm{pH} 7.4$ and $37{ }^{\circ} \mathrm{C}$

\section{Conclusions}

From the results obtained, one can be concluded the following:

Ketotifen fumarate can be prepared successfully as conventional and hollow-type rectal suppositories. The drug release was better from hydrophilic base (PEGs) suppositories in comparison with fatty base (SSG) suppositories. Conventional and hollow type suppositories showed high percent of $\mathrm{KF}$ release when utilized a mixture of PEG 400 and PEG 4000 base at a ratio (70:30). Also, the mixture of PEG 400 and PEG 6000 showed high release when formulated as conventional suppository at same ratio. The impaired release of KF from fatty base (SSG) can be enhanced by adding surfactant (Tween 80 ) at percent of $1 \%$. Hollow-type suppositories are a promising approach for enhancing the release of drugs 
8- Remington's, The Science and Practice administered rectally. Formula 1 exhibited good stability during 30 days at 4 and $25^{\circ} \mathrm{C}$.

\section{References}

Ansel H., Allen L. Popovich N. Pharmaceutical dosage form and drug delivery system.8th.

ed.

Li 10-

ppincott Williams and Wilkins, 2005; $p$. 281-335.

Delik E., Nilifer T. "Ketoprofen sustained release suppositories containing HPMC phthalate in polyethylene glycol bases". International Journal of Pharmaceutics, 1995; 13: 65-74.

11- Allen LV, Worthen DB, Mink B, " Quality Toshihito T., KasumitsuY. "Design of controlled release morphine suppositories containing poly glycerol ester of fatty acid". Biology of Pharmacological Bulletin, 2005; 28 (8),121480-1484.

Chalakanti Suryakumari, A.Anusha, P.Anitha and D.Ravindra. "Formulation and Evaluation of Cow Ghee as Base Fast and Sustained Release Chloroquine Phosphate Suppositories". World Journal of Pharmacy and Pharmaceutical Sciences. 2014;133(6):1493-1509.

5- Japanese Pharmacopoeia, 15th edition, 2007.

Block JH, Beale JM (Eds.), Wilson andl4Gisvold's textbook of organic medicinal and pharmaceutical chemistry, 12th ed., Philadelphia: lippincott Williams and Wilkins. 2011; p. 952.

Sweetman SS, Martindale: The Complete Drug Reference, 36th ed., London: Pharmaceutical Press. 2009; p. 582. of Pharmacy, 19th Ed. Mack Publishing Company. Easton, PA. 1995; p. 1591-1595. Kaewnopparst N., Kaewnopparat S., and Rojanarat W.", Enhanced Release of Diazepam From Hollow Type Suppositories".

International Journal of Pharmaceutical Compounding. 2004; 8:310-312.

Watanabe Y., Matsumoto Y., Baba K. and Matsumoto M.," Pharmaceutical Evaluation of hollow-type suppositories. IV. Improvement of bioavailability of propranolol in rabbits after rectal administration". J. Pharmacobio-Dyn. 1999; 9: 526-531. control of suppositories". In: Suppositories. London: Pharmaceutical Press. 2007; p. 139-189.

Al-Khedairy E. B.H. " (A study on factors affecting the preparation and invitro evaluation of mucoadhesive propranolol $\mathrm{HCl}$ suppositories" Kerbala Journal of Pharmaceutical Sciences, 2013 ; p. 5:115

Aulton's Pharmaceutics: The Design \&Manufacture of Medicines. 3rd ed. London: Churchill Livingstone. 2008; p. 606-614.

Varsheny H. M., Chatterjee A. "Formulation, evaluation and In-Vitro release characteristic of Zaltoprofen suppositories". Asian J Pharm Clin Re, 2012; 5 (4) :235-238

15- "British Pharmacopoeia" The stationary office, London. 2009. 
16- Yousif H. S. " Formulation of Tinidazole rectal suppositories " AJPS, 2011, 10(2) :68-83

17- Realdon N. et al. "Effect of surfactant characteristics on drug availability from suppositories" pharmazie. 2008. Jun;63(6):459-63

18- Thwainy I.G, "In vitro availability of trimethoprim and sulfamethoxazole from suppository dosage form", [MSC thesis]. Baghdad University, College of Pharmacy. 1986.

19- Ibrahim E. H., El-Faham T. H., Mohammed F.A., El-Eraky N. S., "Formulation and in Vitro Release and Bioavailability Study of Domperidone Rectal suppositories". Int. Journal of Innovations Pharm. Sci. 2012; 1 (1):8-14.

20- Stiens, Luttrel, Binard. "Polyethylene glycol versus vegetable oil based bisacodyl suppositories to initiate sidelying bowel care: a clinical trial in persons with spinal cord injury". 1998; 36(11): 777-781.

21- Ramadan A. A. "Formulation and evaluation of bioadhesive vaginal suppository containing Miconazole Nitrate " International Journal of Pharma and Bio Sciences , 2013; 4(1): $455-472$

22- Shrestha A. , Effect of Span80Tween80 mixture composition on the stability of sunflower oil based emultion. National Institute of Technology Rourkela , 201 1; p. 2315

23- Margaret I., Ifudu N. D, Jimson O. " Assessment of the effect of base type and surfactant on the release properties and kinetics of 
paracetamol suppositories" Journal of Chemical and pharmaceutical Research , 2012; 4(6): 3280-3286

24- Reddy MKK, Rao BN, Reddy KR. "Study on Effect of Excipients in Enhancing the Solubility of Nateglinide by Solid Dispersions". Asian Pharm. 2012; 2(1): 4-7.

25- Yu-Li Lo, Yijun Lin and Hong-Ru Lin, "Evaluation of Epirubicin in Thermogelling and Bioadhesive Liquid and Solid Suppository Formulations for Rectal Administration". International Journal of Molecular Sciences. 2014; 15: 342-360.

Matsumoto $Y$, Watanabe $Y$, Yamamoto I, Matsumoto $M$. "Difference in rectal absorption of morphine from hollow-type and conventional suppositories in rabbits". Biol. Pharm. Bull. 1993; 16: 150-153.

\section{ACKNOWLEDGMENT}

Authors would like to express their sincere gratitude and appreciation to the Department of Pharmaceutics/College of pharmacy/University of Baghdad, Baghdad, Iraq for their support. 